\title{
Entrevistando professores da disciplina Arte que lecionam o conteúdo música: encontro entre identidades profissionais
}

\begin{abstract}
Resumo - O presente artigo problematiza os resultados de uma pesquisa de mestrado na qual foram entrevistadas professoras de artes que lecionam o conteúdo música no contexto educacional do sudoeste do Paraná. O estudo centra-se na área da Educação Musical versando a lei 11.769/08 que reza a inserção da Música na educação básica como conteúdo obrigatório. A coleta de dados da pesquisa foi realizada no ano de 2009 . Os objetivos propostos para o desenvolvimento desta pesquisa dizem respeito a transitar pelas narrativas das docentes, relativas à identidade das mesmas enquanto professoras da disciplina Arte. A metodologia utilizada é de abordagem qualitativa, cujos dados foram coletados a partir de entrevistas de História Oral Temática. As participantes da pesquisa foram sete professoras de escolas estaduais do núcleo regional de Pato Branco no estado do Paraná. $\mathrm{Na}$ análise de dados, problematiza-se a formação e atuação dos professores, as visões sobre as diversas linguagens artísticas e a possível abordagem dos conteúdos de Música pelo professor/a com formação em Artes Visuais. Ambiciona-se que as professoras entrevistadas e os leitores deste artigo, por empatia, possam olhar para a atuação profissional com uma nova perspectiva que auxilie a "ser um professor/a" mais crítico e consciente das possibilidades que a Arte traz. Desta forma, almeja-se contribuir para o estudo de narrativas de professores/as, dos problemas específicos da disciplina Arte na escola básica e dos encaminhamentos da implementação da lei 11.769/08.
\end{abstract}

Palavras Chave: Narrativas; Identidade profissional; Professores de Escola Básica; Disciplina Arte; Lei 11.769/08; Educação Musical.

ABSTRACT: This article discusses the results of a master research in which were interviewed art teachers who teach music in the educational context of southwest Paraná. It centers in the area of Music Education, according to the law number 11.769/08, which establish the teaching of Music in Elementary and High schools as mandatory content. The interviews are conducted in 2009. The objectives proposed to the development of this research refer to the wonders among teachers' narratives related to their identities as teachers of the Art discipline. The methodology employed in this research is qualitative approach, whose data were collected from interviews within the Thematic Oral History approach. The participants were seven teachers of Public schools from the regional nucleus of Pato Branco, in the State of Paraná. The analysis of the data focus on the professional experience and acting, the teacher's view concerning the diverse artistic languages and the possible approach of musical contents by the teacher graduated in Visual Arts. It is ambitioned that the teachers interviewed, as well as the readers of this paper, may look, via empathy, at their professional acting with a new perspective which helps them "to be a teacher" more critic and aware of the possibilities that Art brings beyond its multiple challenges. By doing so, it is longed for to contribute to the study of teachers' narratives, the specific problems involving Art discipline in Elementary and High schools and the directions resulting from the implementation of Brazilian law number 11.769/08.

Keywords: Narrative; Identity; Basic School Teachers; Subject Arts; Law 11.769/08; Music Education. 


\section{A BUSCA DO ENCANTAMENTO}

Falar de leis, muitas vezes, pode ser algo impositivo. Por isso, opta-se por uma metodologia de pesquisa que dialoga com os professores. Para, além da letra da lei, buscar os relatos daquelas que se submetem ou não a cumpri-la. Durante este desenvolvimento houve muitas dificuldades, as quais emolduram as subjetivações do processo na busca de sabedoria pessoal que caminhou concomitantemente a esta efetivação, e que está partilhado, em partes, com os leitores do presente artigo.

As implicações da lei $11.769 / 08^{1}$ podem ser estudadas a partir de muitos enfoques. Para a pesquisa de mestrado que é relatada neste artigo pareceu interessante ouvir o professor/a de Arte do sudoeste do Paraná ao qual se impõe o cumprimento da lei. Talvez fosse natural escutar o professor Licenciado em Música, considerando que, na área, ele parece ser a pessoa designada a dar aulas de música. No entanto, os debates nos mostram que não fica claro, principalmente, por causa do veto ${ }^{2}$, quem é este personagem que dará aula de música no ensino básico, a partir do momento em que a música se torna um componente curricular obrigatório. Entretanto, para além desta controvérsia, preocupe-se em ouvir o professor de Arte - mesmo que eu esteja inserido no grupo daqueles que defendem concursos públicos para Licenciados em Música - pois considerei que este professor/a "se fabrica no interior de certos aparatos (...) de subjetivação." (Larrosa, 1994, p.3). Tais aparatos de subjetivação são analisados em uma "dimensão mais geral da educação que (...) tem a ver com a antropologia da educação, isto é, com as teorias e práticas pedagógicas enquanto produtoras de pessoas." (Larrosa, 1994, p.3).

A fala das professoras nas entrevistas de história oral temática conduziu à possibilidade de compreender como estes aparatos de subjetivação se articulam na narração de processos identitidários (Dubar, 1997). Desta forma, questões ligadas aos debates da área de Educação Musical sobre práticas pedagógicas como - que categoria de profissional (diplomados com Licenciatura em Música, Educação Artística, Artes

\footnotetext{
1 Muito embora em 2012 esta lei esteja sendo novamente discutida no legislativo, no momento da realização da pesquisa ela se encontrava plenamente em vigor.

${ }^{2}$ Razões do veto "No tocante ao parágrafo único do art. 62, é necessário que se tenha muita clareza sobre o que significa 'formação específica na área'. Vale ressaltar que a música é uma prática social e que no Brasil existem diversos profissionais atuantes nessa área sem formação acadêmica ou oficial em música e que são reconhecidos nacionalmente. Esses profissionais estariam impossibilitados de ministrar tal conteúdo na maneira em que este dispositivo está proposto.

Adicionalmente, esta exigência vai além da definição de uma diretriz curricular e estabelece, sem precedentes, uma formação específica para a transferência de um conteúdo. Note-se que não há qualquer exigência de formação específica para Matemática, Física, Biologia etc. Nem mesmo quando a Lei de Diretrizes e Bases da Educação Nacional define conteúdos mais específicos como os relacionados a diferentes culturas e etnias (art. 26, § 40) e de língua estrangeira (art. 26, § 50), ela estabelece qual seria a formação mínima daqueles que passariam a ministrar esses conteúdos."

Essas, Senhor Presidente, as razões que me levaram a vetar o dispositivo acima mencionado do projeto em causa, as quais ora submeto à elevada apreciação dos Senhores Membros do Congresso.
} 
visuais, pedagogia), ou, como um professor com pouco estudo formal em música pode ensinar este conteúdo? - são tratadas pelo viés da fabricação dos aparatos de subjetivação dos professores/as. Buscando ampliar os argumentos constitutivos do debate sobre estes pontos polêmicos para a área de Educação Musical, e a área de Arte, a partir de um olhar para as subjetivações do professor/a.

Considerar as circunstâncias legais que circundam as aulas de Arte faz-se relevante, não apenas para profissionais licenciado em Música, mas para toda a área de Arte, uma vez que o desafio da inclusão do conteúdo música se impõe, por força da lei, para as escolas que tem especialista em música e àquelas que não os tem.

Detectar a dificuldade de implementação da Música na escola de Educação Básica, bem como as características do funcionamento das escolas do sudoeste do Paraná, nas quais cabe ao professor/a de Arte - mesmo não habilitado em Música - a responsabilidade de selecionar os conteúdos e as atividades a serem utilizadas em sala de aula são dados que ajudam a pensar a melhor maneira de inseri-la nessas escolas. Desse modo, percebe-se a importância do papel do professor/a na reestruturação e organização do ensinar e aprender Música. Responsabilidade que recai sobre suas escolhas didático-pedagógicas ao organizar as várias áreas de aprendizagem em Arte.

Refletir sobre a inserção da Música pela referida lei, a formação dos professores/as de Arte e o contexto educacional encontrado no Sudoeste do Paraná leva à delimitação do problema em estudo, que se traduz por meio da análise das narrativas de sete educadoras, sendo questionadas sobre o processo de construção de suas identidades profissionais enquanto professoras de Arte.

\section{Aspectos teórico-metodológicos da pesquisa 2.1 A CONSTITUIÇÃO DA IDENTIDADE}

A identidade cultural enfocada, de maneira particular, é a identidade do professor/a de Arte do contexto do sudoeste do Paraná, considerando aspectos que possam estar implicados em sua identidade profissional. O que está acontecendo com essa identidade no contexto histórico que a Educação Musical está vivenciando? Especificamente, em nível histórico, como as identidades dos professores/as de Arte dessa região estão sendo afetadas com a lei 11.769/08?

Ao ocupar-nos com o conceito de identidade, Hall (2006) chama a atenção para a complexidade dessa terminologia, por ser "pouco compreendida na ciência social contemporânea para ser definitivamente posto à prova" (Hall, 2006, p.8). 
No meio escolar, as áreas de conhecimento constituem-se numa das principais fontes de identidade do professor/a. Ao se definirem enquanto pessoas, algumas vezes, dizem que são professores/as de Arte, Português, Matemática, Ciências, Geografia, etc. Por esses elementos não estarem impressos em seus genes, esta definição é tratada de forma metafórica. Entretanto, são impressões que nos levam a pensar tal constituição profissional como essencial.

\begin{abstract}
A divisão intrínseca à identidade tem de, finalmente, e, sobretudo, ser esclarecida pela dualidade da sua própria definição: identidade para si e identidade para o outro são inseparáveis e estão ligadas de uma forma problemática. (...) Eu nunca posso ter certeza que a minha identidade para mim confunde com a minha identidade para o Outro. A identidade nunca é dada, é sempre construída e a (re) construir numa incerteza maior ou menor é mais ou menos durável (DUBAR, 1997, p.104).
\end{abstract}

O argumento defendido é que o professor/a não nasce com essa identidade. Ele é formado e transformado no interior da representação. Nós sabemos como é ser professor/a pelo modo que essa classe é representada em seu conjunto de significados. O professor/a não deve ser visto apenas como o membro de uma classe de um grupo social dentro de uma visão de classificação sociológica, "fulano/a é professor/a". Mas que se torna professor/a pelas maneiras como ele se diz e se pensa. O professor/a desse contexto se representa como um professor/a de Arte - não habilitado em Música - que eventualmente pode dar aula de Música; é a maneira como muitas das professoras entrevistadas pareceram se representar.

A tradição reforça a prática de certos valores e normas de comportamentos através da repetição, o que implica na continuidade de um passado histórico adequado. Pode ocorrer que os elementos essenciais do caráter do professor/a permaneçam imutáveis, apesar de todas as mudanças da história. Por exemplo, nada parece ser mais antigo do que o discurso da polivalência, o que se contradiz com a prática do professor/a de Arte do contexto do sudoeste do Paraná. Com poucas exceções, alguém que se vê pertencente a um discurso que o faz trabalhar articulando as quatro áreas do conhecimento em Arte, quando sua formação é específica em uma área.

O que está problematizando a identidade do professor/a de Arte no contexto do sudoeste do Paraná? Há um complexo processo de mudança, que pode ser sintetizado sob o termo da lei $11.769 / 08$. Pode o referido processo estar gerando um constrangimento a esse profissional? Que impacto essa lei tem sobre a identidade deles? Outro importante questionamento seria por que o profissional formado em uma linguagem se submete à obrigatoriedade de ensinar outras áreas?

Sabemos que uma das principais características da lei, em determinadas circunstâncias, é a aceleração dos processos. Neste caso, a aceleração da inserção do conteúdo música. No entanto, os eventos em um determinado lugar têm um impacto 
imediato, enquanto em outros o processo é mais moroso. A distância entre o que se propõe com a escrita da lei e o que está sendo posto em prática, em certos casos, é imensa.

\section{2- O ACOLHIMENTO DOS DADOS}

Ao tratar do contexto educacional do sudoeste do Paraná, restringe-se ao núcleo regional de Pato Branco (NRE) que consta, segundo a coordenadora de Arte desse estabelecimento, de 47 colégios, 28 escolas e um total de 115 professores/as atuando na disciplina de Arte. Desses, 40 são QPMs (Quadro profissional do magistério) com formação em Arte sendo, em sua maioria, Artes Visuais. Ainda, 49 professores/as PSS (Processo Seletivo Substituto) formados na área ou acadêmicos em processo formativo. Por falta de profissionais habilitados, coexiste uma realidade não muito favorável à Arte. Professores/as com outras formações atuando na disciplina: Língua Portuguesa - 12, Língua Estrangeira Moderna - 2, Matemática - 1, Pedagogia - 1, Publicidade e Propaganda - 2, Educação Física - 1, Outras formações 7, desses últimos a coordenação ainda não havia conseguido a informação sobre a área de formação, na ocasião da coleta de dados da pesquisa, no ano de 2009. Dentre esses professores/as, sete foram entrevistados, sendo dois do município de Chopinzinho, dois de Coronel Vivida e três de Pato Branco.

Para esta pesquisa optou-se pela metodologia de entrevistas de história oral temática, considerando-a uma metodologia no qual o entrevistado fala de suas experiências de vida, focalizando um determinado período de tempo ou situação; o fato da maioria dos participantes serem formados em Artes Visuais, Educação Artística e estarem convocados a dar aula de música por força da nova lei.

\section{Alguns recortes da análise de dados}

\section{1- Professoras de Arte falando sobre ensino de Música: formação, (re)significações e reflexões}

Ouvir as professoras de Arte é atentar a todo processo de contínuo (re)pensar a profissão, seus questionamentos em relação ao trabalho e seus posicionamentos frente aos desafios profissionais. Em alguns relatos, as vivências com Música são parte do processo à escolha da disciplina Arte, como na declaração de uma professora que "tinha 
habilidades para trabalhar com Arte, com músicas, com brincadeiras" e que deveria fazer faculdade de Arte.

Josso (2004) nos revela que os processos formativos são muito complexos, argumentando em relação à generalização relativa que "o termo generalização relativa sublinha, pois a indispensabilidade de ter em conta as dimensões socioculturais dos públicos com que trabalhamos" (p.233). Nesta análise, pretende-se uma generalização relativa tomada à complexidade da História de Vida das professoras e o recorte de narrativas sobre o conteúdo música nele considerado.

A professora Ivone ${ }^{3}$ conta sobre certo professor de música, ao mesmo tempo em que descreve seu fascínio por dança e teatro, demonstrando uma formação bastante diversificada em Arte.

[...] Este professor que eu tive que era de música. A família dele toda eram músicos. De vez em quando ele levava a família toda para a sala de aula pra dar umas aulas bem bacanas. [...] Mas eu gostava muito mesmo da professora Eliete que trabalhava teatro e dança. Que era assim a que eu tinha mais paixão. Ela era dinâmica. A gente saía da sala de aula e fazíamos um monte de coisas ao ar livre. O pessoal das outras salas saiam pra olhar - o que esses loucos estão aprontando? [...] Acho que foram duas faculdades ao mesmo tempo. Uma de vida e a outra de conhecimento na área (Ivone, p. 2).

Louro e Medeiros (2005), entre outros autores, destacam como a reflexão sobre a influência dos antigos professores pode superar uma simples herança pedagógica (NETTL, 1995), na qual o professor se espelha, sem um olhar crítico, nos antigos professores, levando a uma (re)significação das experiências formativas.

As professoras, ao regatarem as memórias de formação em relação seus aos antigos professores/as, reconstroem-se dentro do ato de se narrarem, problematizando suas crenças pedagógicas. Deste modo, quando Tânia fala que seus professores/as trabalhavam de um "jeito despojado, de forma natural", ela aponta para uma abordagem que, provavelmente, também toma na prática pedagógica. Estas opções fazem parte da construção da identidade profissional das professoras. Mesmo que o foco desta pesquisa fosse o conteúdo música, tomada a metodologia de história oral temática, deve-se ouvir sobre este tema dentro das memórias e narrativas, muitas vezes, mais amplas das professoras.

\footnotetext{
${ }^{3}$ As professoras manifestaram, por meio de um documento escrito, a vontade de que seus nomes verdadeiros fossem citados.
} 


\section{2- "Quanto à legislação, eu peco"}

Uma das grandes dificuldades da leitura da lei que rege o ensino de Arte no Brasil, que pode ter ocorrido também no sistema de educação do sudoeste do Paraná, é a legitimação do pensamento de Arte como Artes Visuais. Então, quando o art. $1^{\circ}$ da Lei 11.769/08, que faz menção à alteração do art. 26 da Lei no 9.394, de 20 de dezembro de 1996, que passou a vigorar acrescido do $\S 6^{\circ}$, que diz que a Música deverá ser conteúdo obrigatório, mas não exclusivo, do componente curricular de que trata o $\S 20$ deste artigo que, por sua vez, trata do ensino da Arte como componente curricular obrigatório nos diversos níveis da educação básica, de forma a promover o desenvolvimento cultural dos educandos, interpretou-se que o ensino da Música não seria em uma disciplina específica. Conforme Penna (2002, p. 11) "os parâmetros para os ensinos fundamental e médio estabelecem potencialmente um espaço para Música dentro do conteúdo curricular 'Arte', a sua efetivação depende das decisões pedagógicas de cada escola". A mesma autora pondera em relação ao predomínio histórico das Artes Visuais no que se refere à lei 5.692/71. Penna também realça a falta de clareza da legislação em relação à formação do professor/a de Arte. Com a implementação das diretrizes nacionais para a formação de professores/as da área, fica posta a graduação em cada linguagem específica; embora os concursos, por muito tempo, continuem sendo feitos para uma atuação polivalente.

Uma das professoras relata que, ao que tudo indica, no cotidiano escolar, existe uma cobrança social, ainda que implícita, do professor/a de Arte ensinar as quatro linguagens:

\footnotetext{
O professor não é obrigado a trabalhar essas articulações, ou seja, trabalhar essas quatro áreas. Ele não tem essa obrigatoriedade. Daí a gente se depara com a questão do direito do aluno. A gente vê uma cobrança social. Ela sugere, entre aspas, que o professor trabalhe essas quatro áreas. Entre aspas, porque na verdade cria-se uma obrigatoriedade sim. Então tem uma questão social que pressiona. Pressiona sim. Porque se você não trabalha as quatro áreas o aluno também não se apropria. E a condição que ele tem de se apropriar quando ele não tem outros acessos é a escola.(...). Bem aparente dessa articulação de se trabalhar as quatro áreas e não fica a contento não fica a contento não (Tânia Mara, p. 4 e 5).
}

Na fala da professora Tânia, percebemos certa dicotomia em relação ao ensino de Arte. No entanto, se nos voltarmos para a pessoa do professor/a, percebemos que é um "desafio de gigante" lecionar fora da área de formação. Apegarmo-nos ao discurso de que o educando ficaria sem a possibilidade do conhecimento revela uma questão contrapontística que é a de que tipo de conhecimento se está falando. Seria voltarmos a uma prática polivalente mostrada, por exemplo, na lei de 1971, que quase extinguiu não só o ensino de Música nas escolas, mas houve a diluição em todas as áreas artísticas. 
Não é negado aqui de que conquistas aconteceram. Embora houvesse essa diluição, a legislação educacional estabeleceu um espaço para as Artes na educação básica. A Lei n.0 5.692, de1971, em seu artigo 70, determinava como "obrigatória a inclusão" da Educação Artística "nos currículos plenos dos estabelecimentos de $1^{\circ}$ e $2^{\circ}$ Graus", desse modo, garantiam um espaço na educação escolar às diversas linguagens artísticas. Então, o que se discute seria a implantação da Educação Artística marcada pela proposta polivalente, que concebia uma abordagem integrada das linguagens artísticas e, como consequência, a diluição do conhecimento. Contudo, o discurso em defesa desse modelo ainda está presente.

\begin{abstract}
Eu defendo a polivalência. Sempre defendi. Porque acho que a minha geração conseguiu muito no campo da Arte. Então eu defendo que os cursos deveriam continuar sendo polivalentes e terem uma duração maior para se sair com um preparo melhor nessas áreas. Se nós analisarmos as outras áreas de conhecimento, vamos perceber que a educação básica não tem como objetivo formar profissionais da Educação Física, profissionais das Artes, profissionais das Ciências. Então, também, nós temos que ter isso em mente. Nós vamos trabalhar a educação básica. E pra ser professor de Educação básica você pode ser polivalente sim. O professor de educação física ele ensina basquete, ele ensina futebol, ele ensina vôlei e não é especialista em nenhuma dessas áreas. O professor de ciências ensina química, física e ele não precisa ser especialista. De quinta a oitava série é ciência, não é química, nem física, nem biologia. É um professor generalista. Então porque que o professor de Artes também não pode ser generalista. Eu defendo a formação polivalente de cinco anos. É um bom profissional para trabalhar na educação básica (Maria Angela, p.3).
\end{abstract}

Um ano a mais de formação resolveria tudo na profissão do professor/a de Arte? Mas esta discussão está encerrada pelo menos do ponto de vista das DCN, que normatizam cursos superiores em cada área artística. Falta-nos, por conseguinte, uma discussão clara junto às secretarias de educação e com os professores/as que atuam nas escolas. Precisamos ter cautela para não nos acostumarmos a práticas inconsistentes. Em Música, muitos educadores analisam o texto da canção e dizem que estão incluindo Música na escola. Isto é polivalência? Concordo com a professora que não precisamos ser artistas para sermos professores. São profissões distintas, mesmo que não sejam excludentes entre si, mas a vivência, a reflexão e a experiência com cada linguagem artística precisam ser assumidas, e não mascaradas em algumas poucas atividades.

A lei $11.769 / 08$ parece ser mais contundente ao tratar especificamente 0 assunto da Música como obrigatoriedade. Entretanto, o vácuo entre legislação e sociedade, do qual nos fala Penna (2004), pode vir a impedir a presença da música nas escolas.

Olhar para o professor/a é percebê-lo como peça fundamental desse quebra cabeça. Problemas como o das professoras de Arte do sudoeste do Paraná parecem apontar uma postura entre o desconhecimento da nova lei, sua aplicação apenas em parte, de forma improvisada, ou seu total descumprimento percebido no seguinte trecho narrativo 


\begin{abstract}
A legislação obriga né? Eu acho que no meu caso, na realidade, no meu dia a dia, eu não cumpro essa legislação porque eu não tenho domínio da música. Como eu já falei, eu cumpro assim o básico. E quanto a gestores eu acho que você tem acesso tem liberdade de trabalhar eles te dão todo apoio no que você precisar pelo menos nas escolas que eu trabalhei. Eu nunca tive problema eles sempre colaboraram e até cobram se você faz ou não faz. E quanto à legislação eu peco hehehehehehe - riso constrangido - (Rosana, p.2).
\end{abstract}

A fala da professora mostra que é possível não ser polivalente com o apoio dos gestores. O que falta, parece, são professores/as habilitados em Música. Se existe essa carência teremos que lutar para que sejam ampliadas as vagas, formar mais licenciados em Música, não necessariamente constranger outros profissionais a aprenderem alguns elementos musicais para ensinarem na escola. Exigir que o professor/a de Artes Visuais lecione Música seria o mesmo que exigir que o professor/a de inglês ensinasse latim, francês ou outro idioma que não o da formação em si.

É claro que o período em que viviam as professoras que foram entrevistadas era de adaptação à lei 11.769. Todavia, podemos observar indícios de possíveis dificuldades para a "volta da Música" na escola. Uma delas seria a questão da falta de profissionais com formação específica na área. A outra seria o desconhecimento da nova lei por profissionais com formação específica como parece estar espelhado na narrativa de Gracielli:

\footnotetext{
Eu ainda desconheço. Eu sei que existe a lei, mas ainda não sei como é que isso vai ser colocado para professor. Mas eu percebo assim, que já existe uma dificuldade hoje de trabalhar música na disciplina de Arte. A minha formação é música, mas eu percebo os professores que tem a formação em Artes Visuais, por exemplo, já existe essa dificuldade. Eu acho, a princípio, meio complicado, pelos profissionais, que a gente sabe que não tem, e pelo espaço também (Gracielli, p. 2).
}

Este pensamento da professora Gracielli concorda com autores como Penna (2004, p.25), quando rezam que a efetiva presença da Música no espaço escolar "depende, fundamentalmente, das decisões pedagógicas de cada escola".

\title{
3.3- Mas seria desejável que estas professoras abordassem os conteúdos da Música?
}

Nas entrevistas, as professoras aclaram que, no 'mundo ideal', haveria um professor/a para cada linguagem. Vivemos nesse mundo? Um professor/a fazendo um pouco de cada área, num curto espaço de tempo, significa manter uma tradição que não deu certo na perspectiva de muitos profissionais da educação e da Arte. Sem querer aprofundar a discussão para além dos limites do presente artigo, alguns argumentos, através dos questionamentos de Russel e Zembylas (2007): 
Mas o que ocorre com a integração nas artes? As artes são integradas no currículo como o mesmo entusiasmo e compromisso que as outras disciplinas? Quais são os indicativos do "valor" e da "eficiência" para as propostas que integram as artes e como estes termos são definidos? Como seu sucesso é medido? Como deveria ser medido? (RUSSEL e ZEMBYLAS, 2007, p.288).

Neste trabalho propõe-se apenas a análise das identidades profissionais das professoras em relação ao conteúdo Música. Problematizando a questão da integração das linguagens artísticas, não na busca de respostas fechadas, mas a reflexões que gerem maiores questionamentos.

No contexto do sudoeste do Paraná, o conteúdo Música já é trabalhado, não só pela força da lei, como também por estar nas diretrizes curriculares do estado, o qual é comentado pela professora Tânia Mara. Mesmo existindo a possibilidade da articulação das quatro áreas proposta pela DCE, outra professora, Elizângela, pondera que até busca trabalhar com o conteúdo Música, mas que o ideal seria um professor/a para cada linguagem. Embora perceba a importância do que trata a lei, depara-se com a inacessibilidade dessa área do conhecimento na sua formação específica, que é Artes Visuais, e que, mesmo "correndo atrás", tem muitas dificuldades para trabalhar. Na opinião de Elizângela, o ideal seria um professor/a com formação específica em Música, porque, por mais que ela se esforce, percebe sua limitação.

Esta posição não é um consenso. A professora Ivone, por exemplo, embora concordando que a realidade ideal seria com um professor/a de formação específica, acredita que a própria faculdade devia formar profissionais capazes de atuar nas diversas linguagens. Por outro, lado a professora Laís argumenta ser possível trabalhar com as diferentes linguagens, mesmo que o ideal seja um professor específico.

\footnotetext{
Se eu fosse estruturar eu colocaria separado, porque é separado. O que acontece nas DCES do Paraná tem os conteúdos estruturantes e aí coloca e até nas minhas falas com o chefe do núcleo setor de artes eles dizem que as quatro áreas elas podem ser trabalhadas em conjunto. E aí seria possível trabalhar. A eu vou estudar Música, montar um musical com a parte cênica e pode ter Dança junto. Apresenta lá. Pode apresentar o artista que pintou no mesmo período. Eu acredito que dá pra trabalhar sim, mas se você conseguisse separar as quatro linguagens o aluno aprenderia mais (Laís, p. 4).
}

Uma coisa seria apontarmos para os pontos comuns das áreas de Arte, o que seria uma prática bem significativa se adotada pela maioria dos educadores. A outra é tomarmos as quatro áreas e adotarmos uma prática limitada aos moldes da polivalência. O processo reflexivo sobre as práticas educacionais por meio das narrativas das professoras aguça a clareza dos fatos e retira-nos da superficialidade sobre a grande área Arte e sua especificidade: a Música. 


\section{4- CONSIDERAÇÕES FINAIS}

O momento de finalizar um trabalho configura-se, muitas vezes, como um abandono. Entretanto, um artigo escrito, após uma pesquisa de mestrado tem as suas limitações. Ora, este texto traz algumas contribuições importantes à reflexão em torno dos caminhos a maior quantidade e qualidade da Música na escola, através do olhar sobre a fala das professoras de Arte. A questão da presença da música na escola, à luz da lei $11.769 / 08$, contribui para o debate que este trabalho pretendeu apresentar.

Em vários momentos das falas das professoras, tive a impressão de que elas trabalham Música, por força de formação específica, de maneira superficial, sem profundidade. Seus exemplos sugerem atividades teóricas, informações sobre Música, não experiências musicais propriamente ditas. Por perceber o conceito que as professoras têm sobre Música na escola, seria necessário debater melhor de que se trata essa experiência musical na escola e que tipo de preparo o profissional deveria ter para atuar com Música neste espaço.

Pode ocorrer que as sugestões de ampliar o número de disciplinas na formação encontrem-se pautado mais na ideia de aumentar o número de informação sobre Música, não necessariamente em ampliar a experiência musical. Particularmente, acreditamos que a polivalência não deveria ser alternativa, em nome da qualidade do que se quer oferecer na escola com qualquer uma das áreas de Arte. Cada uma das linguagens da Arte tem suas especificidades, exige tempo, contato com várias experiências, e não acreditamos que um ano a mais possa mudar a qualidade das experiências.

Em caso da necessidade de que o profissional de Artes Visuais seja preparado musicalmente para trabalhar esse conteúdo em sala de aula, isso deve ser assumido pela coletividade, a partir de estudos e reflexões consistentes sobre o que se espera com o ensino de Música na escola dessa região.

Diante do momento histórico em que nos encontramos, parecem relevantes estudos como o do presente artigo, uma vez que contribui para o debate em torno da implementação da lei 11.769 de diversas maneiras: Em primeiro lugar, é importante ouvir os professores/as, pois, sozinhas, as legislações não modificarão o ensino escolar, ao passo que a ação e reflexão dos professores/as sim. Enfrentamos críticas que consideram as pesquisas da academia muito distantes das realidades escolares. Em segundo lugar, ajuda ao debate resgatar o processo histórico da disciplina Arte, não só como um processo linear, mas como um fenômeno pleno de tensões, idas e vindas, de diferentes construções de significado para diferentes atores.

Assim, para muitos pesquisadores em Educação Musical, parece inegável que seja preciso ensinar as quatro áreas com professores/as específicos, sendo a nossa luta a contratação de especialistas (licenciados) em Música. Todavia, para muitas professoras 
entrevistadas, a polivalência ainda está viva e atuante. Não interessa saber qual o ponto de vista "correto", mas, sim, os questionamentos que podemos levantar em torno da situação controversa que a nova lei parece gerar.

Além disso, mais que questionamentos, problematizar as falas das professoras pode amenizar as possíveis tensões de um dos aspectos pouco confortáveis da sua atuação profissional. Neste sentido, ambiciona-se que elas e os leitores/as desse artigo, por empatia, possam olhar para a sua atuação profissional com uma perspectiva que auxilie no "ser um professor/a" mais crítico e consciente das possibilidades que a Arte traz para além dos seus múltiplos desafios. A realização desta pesquisa possibilitou uma reflexão que ampliará os pontos de vista que nortearão nossa atuação como professores/as de Arte/Música. Enquanto pesquisa, almeja-se contribuir para o estudo de narrativas de professores/as, das problemáticas específicas da disciplina Arte na escola básica, e dos encaminhamentos da implementação crítica e criteriosa da lei 11.769/08 e de todos os debates gerados por ela. 


\section{REFERÊNCIAS BIBLIOGRÁFICAS}

BRASIL. Lei de Diretrizes e Bases da Educação Nacional n. 9394 de 20 de dezembro de 1996, 2001.

BRASIL. Lei de Diretrizes e Bases da Educação Nacional n. 5692 de 11 de agosto de 197 I.

BRASIL. Lei de Diretrizes e Bases da Educação Nacional n. 4024 de 20 de dezembro de 1961.

DUBAR, Claude. A SOCIALIZAÇÃO construção das identidades sociais e profissionais. Porto Editora, Portugal, 1997.

Formação, trabalho e identidade profissionais. In: Canário, Rui - org. Formação e situações de trabalho. Porto Editora, Portugal, 1997.

HALL, Stuart. A identidade cultural na pós-modernidade. Trad. Tomáz Tadeu da Silva e Guacira Lopes Louro. Rio de Janeiro: DP \& A. 2006. $11^{\text {a }}$ ed. ou reimpressão.

JOSSO, Marie-Christine. Experiências de vida e formação. São Paulo: Cortez, 2004. 285 p.

LARROSA, Jorge. Tecnologias do Eu e Educação. In: SILVA, Tomaz Tadeu da. O sujeito da educação - Estudos foucautianos. Petrópolis: Vozes, 1994, p. 35-86.

LOURO, Ana Lúcia. Ser docente universitário - professor de música: dialogando sobre identidades profissionais com professores de instrumento. Porto Alegre, $195 \mathrm{f}$. Tese (Doutorado), Programa de Pós-Graduação em Música, Universidade Federal do Rio Grande do Sul, Porto Alegre, 2004.

Narrativas de docentes universitários-professores de instrumento sobre mídia: da relação "um para um" ao "grande Link" in: Souza, Jusamara (org.) Aprender e Ensinar Música no Cotidiano. Porto Alegre: Sulina, 2008.

NETTL, Bruno. Heartland Excursions: ethnomusicological reflections on schools of music Urbana and Chicago: University of Illinois Press, 1995.

PARANÁ. Secretaria de Estado da Educação. Diretrizes Curriculares de Educação Básica Arte. Departamento de Educação Básica. Curitiba, 2008.

PENNA, Maura. A dupla dimensão da política educacional e a música na escola: I analisando a legislação e termos normativos. Revista da ABEM, Porto Alegre, V. 10, 1928, mar. 2004. 
A dupla dimensão da política educacional e a música na escola: II - da legislação à prática escolar. Revista da ABEM. Setembro de 2004. p 7-16.

Professores de música nas escolas públicas de ensino fundamental e médio: uma ausência significativa. Revista da ABEM, Porto Alegre, v. 7, 7-19, set. 2002.

RUSSEL, Joan. E ZEMBYLAS, Michalinos. Arts Integration in the curriculom: a review of research and implications for teacher and learning IN: BRESLER, Liora. International Handbook of Research in Arts Education. Dordrecht: Springer, 2007. p. 287-301.

Alysson Custódio Amaral (SMEC)

Ana Lucia de Marque e Louro-Hettwer (UFSM)

Recebido em: 13/11/2012

Aprovado em: 15/01/2013 